\title{
PERIOPERATIVE NEPHRECTOMY MANAGEMENT: INTRADURAL MORPHINE VERSUS SERRATUS INTERCOSTAL BLOCK
}

R. López Herrero, M.A Pérez Herrero, B. Sánchez Quirós, A. Martínez Martín, O. de la Varga Martínez, S. Cocho Crespo Servicio de Anestesia y Reanimación. Hospital Clínico Universitario de Valladolid.

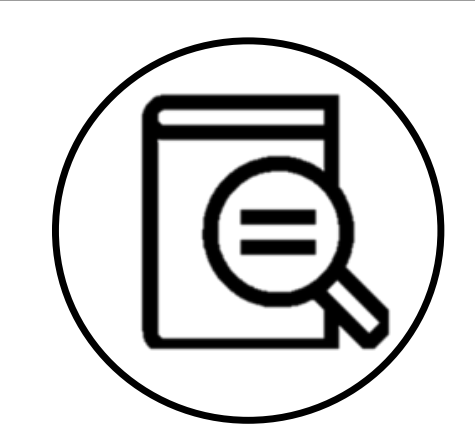

\section{BACKGROUND AND AIMS}

The frequency and intensity of postoperative pain in nephrectomy are high. Despite the evidence-based recommendations management for postoperative pain management, the treatment remains suboptimal. In this study, we compare the safety and efficacy in laparoscopic nephrectomy analgesia between intradural morphine versus serratus intercostal block (SIPB), both of them associated with general anesthesia.

Descriptive and prospective study was conducted in six patients, who were scheduled for elective

laparoscopic nephrectomy. All patients signed informed consent to entry in the study.

The patients were randomly allocated to receive either general anesthesia and intradural morphine $(0,2 \mathrm{mg})$ or general anesthesia and SIPB at $8^{\text {th }}$ intercostal level, with $8 \mathrm{ml}$ bupivacaine $0,25 \%$.

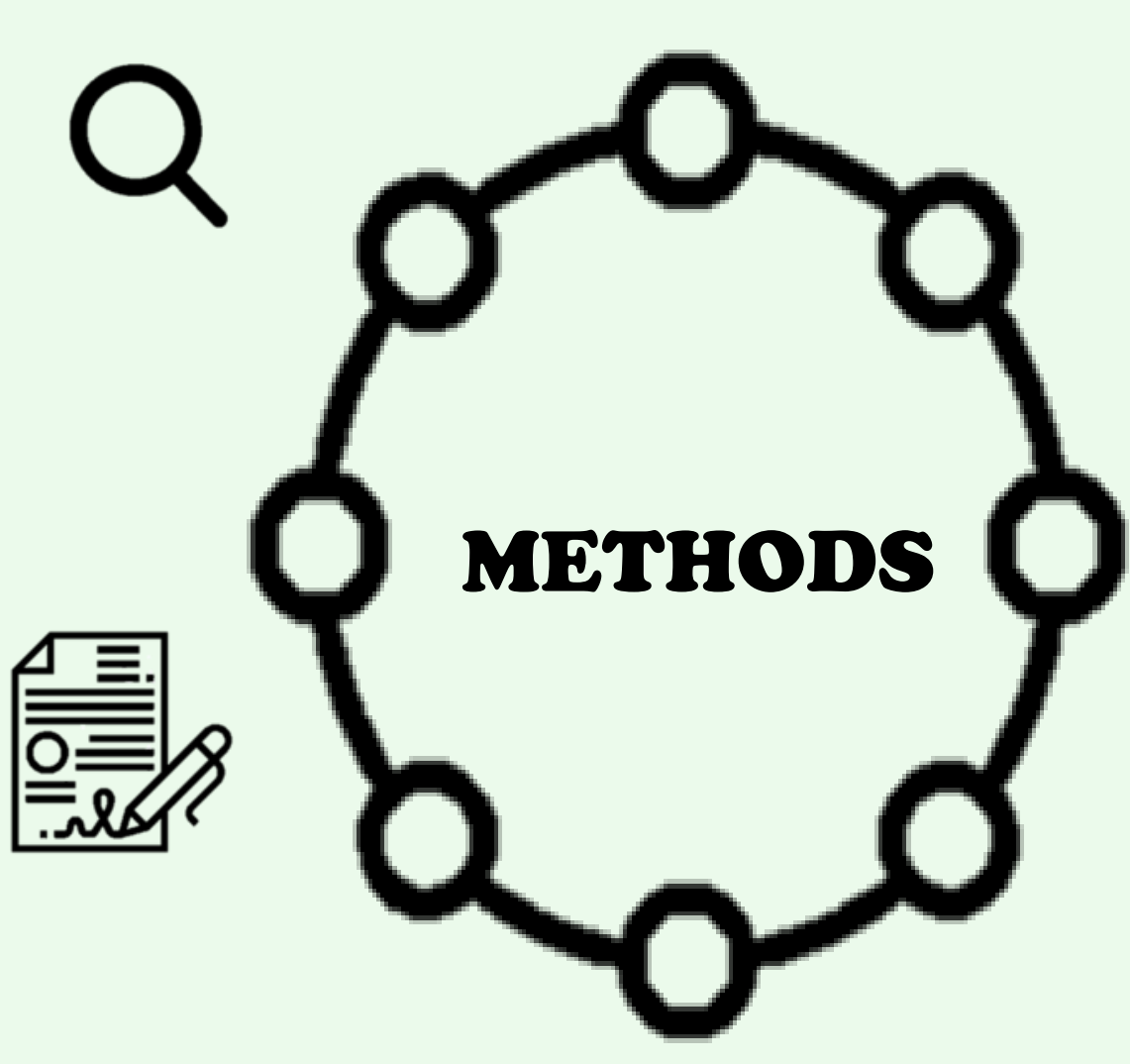

Anesthesia in both groups was induced with IV $2 \mathrm{mg} / \mathrm{kg}$ propofol, 2 $\mu \mathrm{g} / \mathrm{kg}$ fentanyl and muscle relaxation with IV $0.6 \mathrm{mg} / \mathrm{kg}$ rocuronium. Maintenance anesthesia was established with $2 \%$ sevoflurane. Depth of anesthesia was monitored by Sedline, the value of PSI was maintained between 30 and 40. At the end of the operation, suggammadex ( $2 \mathrm{mg} / \mathrm{kg}$ ) iv were applied for the antagonism of the muscle relaxant.

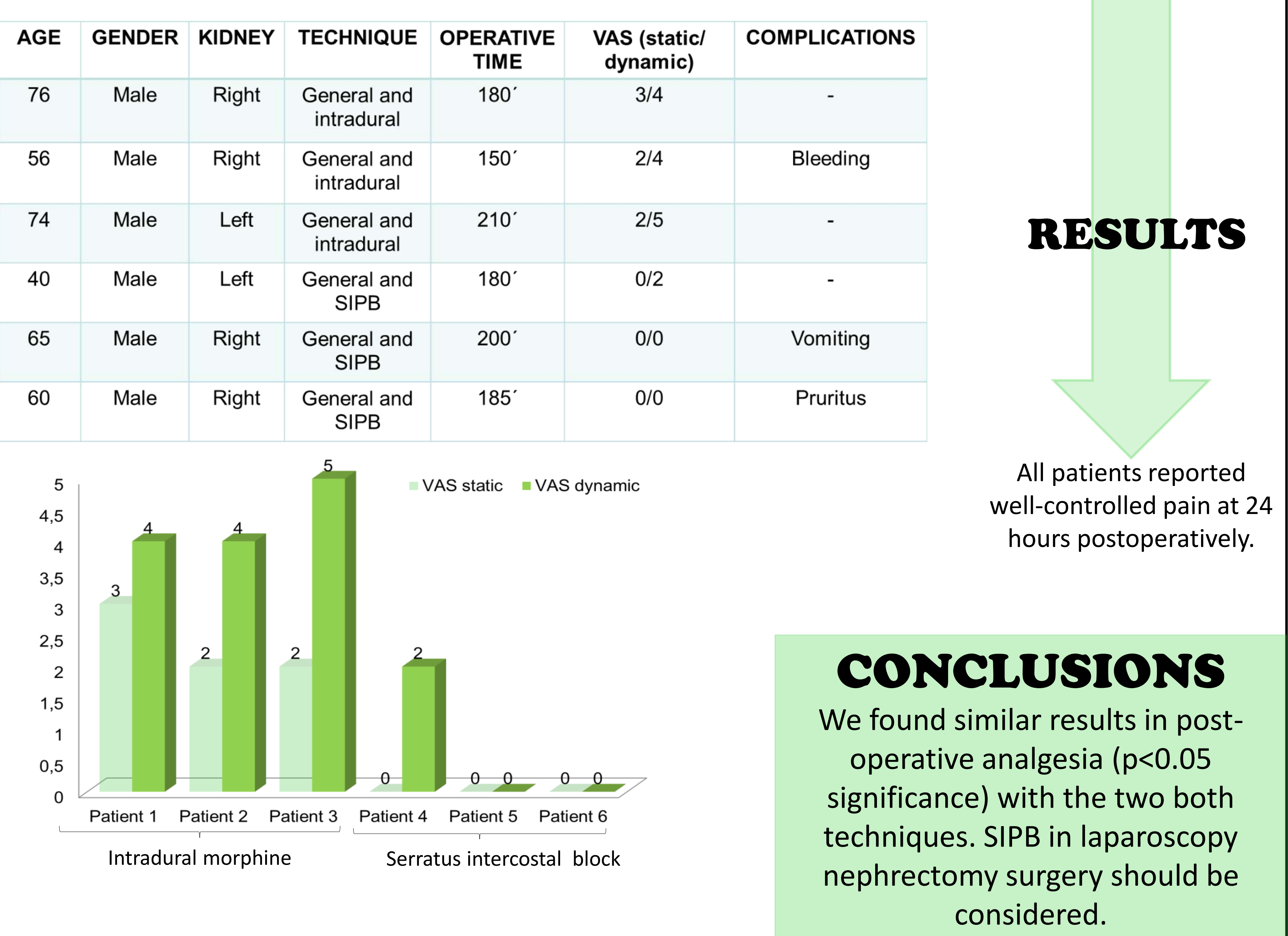

